\title{
Male or female? Brains are intersex
}

\author{
Daphna Joel * \\ Department of Psychology, Tel-Aviv University, Tel-Aviv, Israel
}

\section{Edited by:}

David C. Spray, Albert Einstein College of Medicine, USA

\section{Reviewed by:}

Dumitru A. lacobas, Albert Einstein College of Medicine of Yeshiva University, USA

Anne M. Etgen, Albert Einstein

College of Medicine, USA

*Correspondence:

Daphna Joel, Department of Psychology, Tel-Aviv University, Ramat-Aviv, Tel-Aviv 69978, Israel. e-mail:djoel@post.tau.ac.il
The underlying assumption in popular and scientific publications on sex differences in the brain is that human brains can take one of two forms "male" or "female," and that the differences between these two forms underlie differences between men and women in personality, cognition, emotion, and behavior. Documented sex differences in brain structure are typically taken to support this dimorphic view of the brain. However, neuroanatomical data reveal that sex interacts with other factors in utero and throughout life to determine the structure of the brain, and that because these interactions are complex, the result is a multi-morphic, rather than a dimorphic, brain. More specifically, here I argue that human brains are composed of an ever-changing heterogeneous mosaic of "male" and "female" brain characteristics (rather than being all "male" or all "female") that cannot be aligned on a continuum between a "male brain" and a "female brain." I further suggest that sex differences in the direction of change in the brain mosaic following specific environmental events lead to sex differences in neuropsychiatric disorders.

Keywords: male brain, female brain, sexual differentiation, gender differences, sex differences
The last two decades have seen a resurgence of interest in the ancient question of whether men and women are fundamentally different. Books like You Just Don't Understand, by Tannen (1990) and Men from Mars, Women from Venus, by Gray (1992), present men and women as fundamentally different. More recent books discuss fundamental differences between the brains of boys/men and girls/women (e.g., The Female Brain by Brizendine, 2006, Why Gender Matters by Sax, 2005; Boys and Girls Learn Differently, by Gurian and Henley, 2001), and call for action on the basis of such differences (e.g., single-sex education). The underlying assumption in these publications, as well as in scientific papers on sex differences in the brain (e.g., BaronCohen et al., 2005; Cahill, 2006), is that human brains can take one of two forms, male or female, and that the differences between these two forms underlie differences between boys and girls, men and women, in personality, cognition, emotion, and behavior.

Sex differences in brain structure are indeed well documented. There are sex differences in the size of the brain and of specific brain regions, and in composition of neurons, neurotransmitter content, morphology of dendrites, number of receptors, etc. (for recent reviews see Cahill, 2006; Cosgrove et al., 2007; McCarthy, 2009; Rhodes et al., 2009; Sakuma, 2009; Lenroot and Giedd, 2010; I will use the term brain characteristics to refer to all the characteristics of the brain that may show a sex difference). Yet, the idea that sex differences in the brain lead to sex differences in behavior and cognition has been challenged by several authors on various grounds, including lack of consistency in the literature on sex differences in brain structure; the difficulty to find a simple relation between a sex difference in brain structure and a sex difference in function; demonstrations that some sex differences in brain structure serve to prevent, rather than cause, sex differences in behavior and cognition; and the possibility that sex differences in the adult brain may be the result of sex differences in life experience (e.g., Byne et al., 1988; Rogers, 2001; Fitch and Bimonte, 2002; De Vries, 2004; Hines, 2004; Vidal, 2005; Cahill, 2006; de Vries and Sodersten, 2009; Rhodes et al., 2009; JordanYoung, 2010). However, most of these authors also adhere to the view that anatomically, human brains can take one of two forms, "male" or "female."

The present paper questions this latter view. More specifically, this paper examines the implicit assumption that the fact that many brain characteristics show sex differences means that human brains can take only one of two forms, "male" or "female." The latter will be true only if there is a high degree of match between the "male"/"female" form of all of the brain characteristics in a single brain. Below I review data on sex differences in brain structure and on the influence of environmental events on such differences, and conclude that a perfect match between the "male/female" type of all brain characteristics in a given brain is highly unlikely.

There are only a few brain characteristics for which the term sexually dimorphic, which literally means having two forms, is appropriate, that is, for which there is minimal or no overlap between the form of this characteristic in males and females (e.g., the size of the sexually dimorphic nucleus of the preoptic area, which is three to eight times larger in male rats compared to female rats, Swaab, 1995). For most documented sex differences in the brain, however, and in particular in regions involved in behavior, emotion, and cognition, there is a considerable overlap between the distributions of the two sexes (Juraska, 1991; McCarthy and Konkle, 2005; Cosgrove et al., 2007; Koscik et al., 2009; Lenroot and Giedd, 2010). It follows, that individuals may have the "female" or the "male" form for any of these nondimorphic characteristics. The question then becomes whether the brain of a given individual is homogenous or heterogeneous 


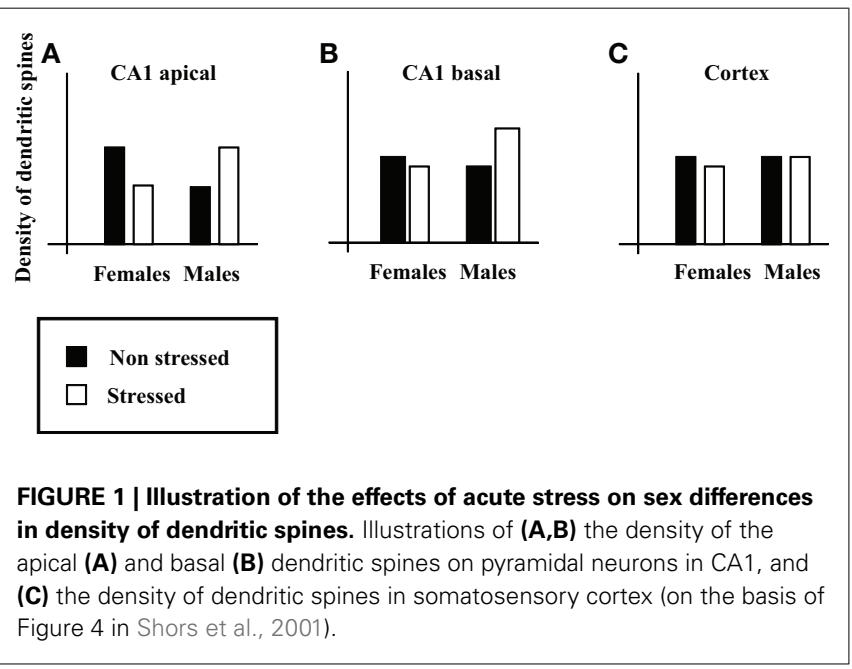

with respect to the "male/female" type of its different brain characteristics ${ }^{1}$.

Current data on the effects of environmental events on brain structure strongly suggest that heterogeneity in the "male/female" type of an individual's brain characteristics is the rule, rather than the exception. Specifically, prenatal and postnatal manipulations (e.g., exposing dams to stress, maternal separation, rearing conditions, early handling, acute and chronic postnatal stress, prenatal exposure to psychoactive drugs, anesthesia) have been shown in rats to reverse, abolish, create, or exaggerate sex differences in brain characteristics. For example, Shors et al. (2001) found that exposure of adult rats to acute stress (a) reversed a sex difference in the density of the apical dendritic spines of pyramidal neurons in area CA1 of the hippocampus (see Figure 1A for illustration); (b) led to the emergence of a sex difference in the density of basal dendritic spines in CA1 (Figure 1B); and (c) had no effect on the density of dendritic spines in the somatosensory cortex (Figure 1C).

Reversal, abolishment, creation, and exaggeration of sex differences in brain structure following environmental manipulations are well documented. Such effects were demonstrated in various brain regions, including the frontal and occipital cortex, hippocampus and related cortical areas, amygdala, cerebellum, brain stem, hypothalamus and corpus callosum; for several neurotransmitter systems, including the glutamatergic, GABAergic, serotonergic, dopaminergic, noradrenergic, and endocannabinoid; and for many brain characteristics, including size, number of neurons, number of glia cells, dendritic morphology, number and size of axons, and density of receptors (e.g., Juraska, 1991; Vathy and Katay, 1992; McCormick et al., 1995; Galea et al., 1997; Vathy, 2001, 2002; Mitsushima et al., 2003; Drossopoulou et al., 2004; Richardson et al., 2006; Wilber et al., 2007; Rothstein et al., 2008;

\footnotetext{
${ }^{1}$ It is noteworthy that the fact that some brain characteristics show dimorphic sex differences whereas others show non-dimorphic sex differences already entails that a considerable number of individuals will have a heterogeneous brain. For example, a female with one or more non-dimorphic brain characteristics with a "male" type and dimorphic brain characteristics with a "female" type. But I make here even a stronger statement. I argue that heterogeneity is the rule in the relations between the different non-dimorphic brain characteristics.
}

Zuena et al., 2008; Fumagalli et al., 2009; Garrett and Wellman, 2009; Lin et al., 2009; McLaughlin et al., 2009; Oomen et al., 2009; Reich et al., 2009; Rhodes et al., 2009; Suarez et al., 2009; Viveros et al., 2009). As in Shors et al. (2001), also in these studies the same manipulation often has different effects on the "male/female" type of different brain characteristics, changing the "male/female" type of some characteristics but not others, thus creating an heterogeneous mosaic of "male" and "female" brain characteristics. Moreover, because different manipulations may result in different changes to the brain's mosaic [e.g., chronic and acute stress have the same sex-dependent effects on some brain characteristics but different sex-dependent effects on other characteristics (e.g., Lin et al., 2009 who show this within a single study)], the "male/female" brain mosaic can take different forms that are not aligned on a continuum between a "male brain" and a "female brain."

We can thus conclude that sex interacts with other factors to determine the structure of the brain (for a similar conclusion see Rogers, 2001; Hines, 2004), and that these interactions are complex. The result is therefore a multi-morphic, rather than a dimorphic, brain, that is, different individuals will have different combinations of "male" and "female" brain characteristics. In this sense brains are neither "male" nor "female," they are "intersex" [intersex refers to individuals for whom the match between the different levels of biological sex (genetic, gonadal, hormonal, and genital) is not perfect (e.g., a person with male chromosomes (XY), male gonads (testes), and female external genitalia, as in complete androgen insensitivity syndrome), or the form of one or more sex characteristics is intermediate between the male and female forms (e.g., ambiguous genitalia), Blackless et al., 2000].

In claiming that brains do not have sex (i.e., that brains cannot be divided into "male" brains and "female" brains ${ }^{2}$ ), I do not claim that we cannot predict one's sex on the basis of the structure of his/her brain. The latter would be possible with accuracy above chance if the "male" $/$ "female" form of a sufficient number of non-dimorphic sex differences were known (although it would be much more accurate and easy to predict one's sex according to the form of his/her external genitalia). We are discussing here the reverse problem, that is, whether we can predict the structure of one's brain on the basis of one's sex. The findings reviewed here lead to the conclusion that although we can predict that on average, females will have more brain characteristics with the "female" form than with the "male" form and vice versa for males, we cannot predict the particular array of "male/female" brain characteristics

\footnotetext{
${ }^{2}$ One can avoid the problem of the multiple forms the brain can take and differentiate between a "male" brain and a "female" brain by restricting the determination of the brain's sex to the morphology of the most dimorphic brain regions. In humans, however, there will still be individuals with an intersex brain even according to this conservative definition, because in humans there is some overlap between the sexes even for the most dimorphic brain characteristics (Allen and Gorski, 1990; Swaab, 1995; Byne et al., 2000; Cordero et al., 2000; Kruijver et al., 2000; Chung et al., 2002; Garcia-Falgueras and Swaab, 2008). A more serious problem to this solution, however, is the fact that the dimorphic regions of the brain are involved mainly in the regulation of reproduction (McCarthy and Konkle, 2005), whereas most interest in a "male" and a "female" brain focuses on sex differences in behavior, cognition, emotion, personality, etc. The brain regions that are involved in these higher functions (e.g., cortex, hippocampus, amygdala) show non-dimorphic sex differences, and are thus arranged in a heterogeneous "male/female" mosaic.
} 
of an individual on the basis of her/his sex (consult for example Figure 1A - knowledge of both sex and recent history regarding exposure to stress is necessary to predict the density of apical dendritic spines on pyramidal neurons in CA1). Yet it is the specific details of a brain mosaic which determine that brain's function. This is because information processing in the brain depends on networks comprising of many brain regions, and because different functions involve different networks. Therefore whether two individuals are similar or not depends on the similarity in the details of their brain mosaic and on the specific function we are interested in, and not on the mere number of "male" and "female" characteristics $^{3}$.

Indeed, decades of psychological research on sex differences have led to the conclusion that although we live in a highly gendered world there are hardly any differences between men and women on most psychological characteristics (e.g., cognitive abilities, personality traits). Even in the few domains in which consistent sex differences are found, the size of the difference is small and there is considerable overlap between the distributions of the two sexes (for review see, Feingold, 1994; Halpern, 1997; Hyde, 2005). Moreover, although it was once believed that the various psychological characteristics and behaviors that do show sex differences contribute to a single Masculinity-Femininity continuum on which individuals may be positioned, it is now accepted that individuals possess a complicated array of masculine and feminine characteristics (personality traits, attitudes, interests, and behaviors) that cannot be captured using a uni-dimensional (Masculinity-Femininity) or a bi-dimensional (High-Masculinity/Low-Masculinity $\times$ HighFemininity/Low-Femininity) model of gender (Spence, 1993; Koestner and Aube, 1995; Egan and Perry, 2001; it is noteworthy that Whalen reached a similar conclusion already in 1974 on the basis of his studies on the hormonal control of the sexual differentiation of behavior in rats, and contrasted his "orthogonal model of differentiation" with the linear model of differentiation which has been prevailing since Phoenix et al. published their work in 1959; Whalen, 1974; Phoenix et al., 1959). The current view of Masculinity and Femininity is the psychological parallel of the anatomical view presented here, namely, that although many

\footnotetext{
${ }^{3}$ In this paper I use a distinction between a "male" and a "female" form of brain characteristics in order to make the point that the brain is an heterogeneous "male/female" mosaic. However, the fact that most sex differences are non-dimorphic and that the existence and direction of sex differences depends on environmental events raises the question re how do we determine what is the "male" and what is the "female" form of a given characteristic? This problem is intensified by the fact that changes in brain structure also occur as a result of normal development and aging, and they do not always have the same course in the two sexes. In the human brain, sex differences in the rate of change have been reported at different levels of organization including the size of the whole brain (Lenroot and Giedd, 2010), the size of specific brain regions (e.g., hippocampus, Bouix et al., 2005), the number of specific types of neurons (e.g., corticotrophin releasing hormone neurons in the hypothalamus, Bao and Swaab, 2007), and the functioning of specific neurotransmitter systems (e.g., dopaminergic, Rhodes et al., 2009). As a result, whether there is a sex difference and its direction depend on the age at which measurements are made (Lenroot and Giedd, 2010). Moreover, in females the form of some brain characteristics is modulated by gonadal hormones and thus fluctuates regularly (McCarthy and Konkle, 2005). I therefore recommend that we start referring to measures of the brain in quantitative ways, using ordinal or interval scales, rather than in qualitative ways, using nominal scales (e.g., "male," "female").
}

brain characteristics show sex differences, the brains of men and women consist of an heterogeneous "male/female" mosaic that cannot be aligned on a continuum between a "male brain" and a "female brain."

More recently, functional imaging studies comparing brain activity in women and men have attempted to distinguish between a "male" and a "female" type of information processing in the brain. However, despite reports of sex differences in imaging studies, different studies of the same task rarely report the same sex differences in brain activity (e.g., Ihnen et al., 2009; Kaiser et al., 2009; Domes et al., 2010). This lack of convergence on a unitary model of how male and female brains might function differently has been attributed to a number of factors including small sample size, differences in the details of the tasks used and in the data processing procedures in different studies, as well as sex differences in task performance and in the cognitive strategies employed (e.g., Haut and Barch, 2006; Plante et al., 2006; Harrington and Farias, 2008; Ihnen et al., 2009; Kaiser et al., 2009; Domes et al., 2010). What these explanations have in common is the assumption that the brains of men and women are different, and that the failures to find consistent sex differences reflect false negative errors. I, in contrast, argue that the failures to find consistent sex differences reflect false positive errors. In other words, I suggest that sex differences found in a single study are a result of comparing two samples randomly drawn from a single heterogeneous population of brains (each brain being a different "male/female" mosaic), rather than the result of comparing two samples, one randomly drawn from a population of "male" brains and the other from a population of "female" brains.

There is at least one area, however, where sex seems to play an important role, and this area is neuro- and psychopathology. There are sex differences in the prevalence, course, and response to treatment of different neuropsychiatric disorders (e.g., Cahill, 2006). Although clearly social and cultural factors contribute to sex differences in neuro/psychopathology, biological factors play an important role. In the context of sex differences in the brain, sex differences in neuropsychiatric disorders have been attributed to sex differences in the structure of the normal brain (e.g., BaronCohen et al., 2005; Cahill, 2006; Cosgrove et al., 2007; Rhodes et al., 2009; Lenroot and Giedd, 2010). The mosaic hypothesis, in contrast, attributes sex differences in neuro/psychopathology to sex differences in the direction of change in the brain mosaic following specific environmental events. To give a very simplistic example, if high spine density in area $\mathrm{X}$ is related to proneness to develop depression, and if acute stress is found to increase spine density in this area in females but decrease it in males, then we can predict that females would be more prone to develop depression following acute stress than males, even if there is no sex difference in this brain characteristic in the population. It follows that the fact that there is a sex difference in the prevalence of a disorder (e.g., autism) does not necessarily mean that this pathology reflects an extreme of the normal (e.g., male) brain (as posited for example by the "extreme male brain" theory, Baron-Cohen et al., 2005).

The suggested conceptualization, which holds that sex affects the direction of change one's brain may take in response to specific events and therefore the likelihood of such events to lead to specific neuropsychiatric disorders, may be viewed as part 
of a more general attempt to study gene-environment interactions in psychiatry. It is now widely accepted that the same environmental event may have different consequences in different individuals because of differences in their genetic background (e.g., Reiss and Neiderhiser, 2000; Fumagalli et al., 2007; Shepard et al., 2009; Rutter, 2010). The present discussion suggests that sex may be modulating some of these geneenvironment interactions. An example to this principle may be found in the recent demonstration in a transgenic mouse model of Alzheimer's disease that stress significantly increased parameters of b-amyloidosis in females but not in males (Devi et al., 2010).

\section{A CONCLUDING REMARK}

Evidence that the structure of the brain is responsive to preand post-natal manipulations and that these may affect sex

\section{REFERENCES}

Allen, L. S., and Gorski, R. A. (1990). Sex difference in the bed nucleus of the stria terminalis of the human brain. J. Comp. Neurol. 302, 697-706.

Arnold, A. P. (2009). The organizational-activational hypothesis as the foundation for a unified theory of sexual differentiation of all mammalian tissues. Horm. Behav. 55, 570-578.

Bao, A. M., and Swaab, D. F. (2007). Gender difference in age-related number of corticotropin-releasing hormone-expressing neurons in the human hypothalamic paraventricular nucleus and the role of sex hormones. Neuroendocrinology 85, 27-36.

Baron-Cohen, S., Knickmeyer, R. C., and Belmonte, M. K. (2005). Sex differences in the brain: implications for explaining autism. Science 310, 819-823.

Blackless, M., Charuvastra, A., Derryck, A., Fausto-Sterling, A., Lauzanne, K., and Lee, E. (2000). How sexually dimorphic are we? Review and synthesis. Am. J. Hum. Biol. 12, 151-166.

Bouix, S., Pruessner, J. C., Louis Collins, D., and Siddiqi, K. (2005). Hippocampal shape analysis using medial surfaces. Neuroimage 25, 1077-1089.

Brizendine, L. (2006). The Female Brain. New York: Morgan Road Books.

Byne, W., Bleier, R., and Houston, L. (1988). Variations in human corpus callosum do not predict gender: a study using magnetic resonance imaging. Behav. Neurosci. 102, 222-227.

Byne, W., Lasco, M. S., Kemether, E., Shinwari, A., Edgar, M. A., Morgello, S., Jones, L. B., and Tobet, S. (2000). The interstitial nuclei of the human anterior hypothalamus: an investigation of sexual variation in volume and cell size, number and density. Brain Res. 856, 254-258.

Cahill, L. (2006). Why sex matters for neuroscience. Nat. Rev. Neurosci. 7, 477-484.

Chung, W. C., De Vries, G. J., and Swaab, D. F. (2002). Sexual differentiation of the bed nucleus of the stria terminalis in humans may extend into adulthood. J. Neurosci. 22, 1027-1033.

Cordero, M. E., Valenzuela, C. Y., Torres, R., and Rodriguez, A. (2000). Sexual dimorphism in number and proportion of neurons in the human median raphe nucleus. Brain Res. Dev. Brain Res. 124, 43-52.

Cosgrove, K. P., Mazure, C. M., and edge of sex differences in brain structure, function, and chemistry. Biol. Psychiatry 62, 847-855.

De Vries, G. J. (2004). Minireview: sex differences in adult and developing brains: compensation, compen145, 1063-1068.

de Vries, G. J., and Sodersten, P. (2009). Sex differences in the brain: the relation between structure and function. Horm. Behav. 55, 589-596.

Devi, L., Alldred, M. J., Ginsberg, S. D., and Ohno, M. (2010). Sex- and brain region-specific acceleration of betaamyloidogenesis following behavioral stress in a mouse model of Alzheimer's disease. Mol. Brain 3, 34.

Domes, G., Schulze, L., Bottger, M., Grossmann, A., Hauenstein, K., Wirtz, P. H., Heinrichs, M., and Herpertz, S. C. (2010). The neural correlates of sex differences in emotional reactivity and emotion regulation. Hum. Brain Mapp. 31, 758-769.

Drossopoulou, G., Antoniou, K., Kitraki, E., Papathanasiou, G., Papalexi, E., Dalla, C., and Papadopoulou-Daifoti, Z. (2004). Staley, J. K. (2007). Evolving knowlsation, compensation. Endocrinology

differences in brain structure is not new (e.g., Juraska, 1991). It has also been noted that sexual differentiation may progress independently in different brain tissues thus enabling genetically and environmentally induced variation in sexual differentiation of different tissues within a single brain (e.g., Simerly, 2002; Hines, 2004; Arnold, 2009; McCarthy et al., 2009; Sakuma, 2009). Yet these effects have typically been treated as increasing variability in brain structure and thus obscuring sex differences (e.g., Juraska, 1991). I would like to stress that I claim that there is no "true dimorphism" that is obscured by genetically and environmentally induced variability. There are no "true" "male" and "female" brains out there to discover. The true nature of the brain is that its form is highly variable. This variability is created by the interaction of genes (on sex chromosomes and on autosomal chromosomes), hormones (gonadal and others) and environment, in utero and throughout life.

Sex differences in behavioral, neurochemical and neuroendocrine effects induced by the forced swim test in rats. Neuroscience 126, 849-857.

Egan, S. K., and Perry, D. G. (2001). Gender identity: a multidimensional analysis with implications for psychosocial adjustment. Dev. Psychol. 37, 451-463.

Feingold, A. (1994). Gender differences in personality: a meta-analysis. Psychol. Bull. 116, 429-456.

Fitch, R. H., and Bimonte, H. A. (2002). "Hormones, brain and behavior: putative biological contributions to cognitive sex differences," in Biology, Society and Behavior: The Development of Sex Differences in Cognition, eds A. McGillicuddy-De Lisi and R. De Lisi (Westport: Ablex Press), 55-91.

Fumagalli, F., Molteni, R., Racagni, G., and Riva, M. A. (2007). Stress during development: impact on neuroplasticity and relevance to psychopathology. Prog. Neurobiol. 81, 197-217.

Fumagalli, F., Pasini, M., Frasca, A., Drago, F., Racagni, G., and Riva, M. A. (2009). Prenatal stress alters glutamatergic system responsiveness in adult rat prefrontal cortex. $\mathrm{J}$. Neurochem. 109, 1733-1744.

Galea, L. A., McEwen, B. S., Tanapat, P., Deak, T., Spencer, R. L., and Dhabhar, F. S. (1997). Sex differences in dendritic atrophy of CA3 pyramidal neurons in response to chronic restraint stress. Neuroscience 81, 689-697.

Garcia-Falgueras, A., and Swaab, D. F. (2008). A sex difference in the hypothalamic uncinate nucleus: relationship to gender identity. Brain 131, 3132-3146.

Garrett, J. E., and Wellman, C. L. (2009). Chronic stress effects on dendritic morphology in medial prefrontal cortex: sex differences and estrogen dependence. Neuroscience 162, 195-207.

Gray, J. (1992). Men Are from Mars, Women Are from Venus: A Practical Guide for Improving Communication and Getting What You Want in Your Relationships. New York: HarperCollins Publishers.

Gurian, M., and Henley, P. (2001). Boys and Girls Learn Differently!: A Guide for Teachers and Parents. San Francisco: John Wiley \& Sons, Inc.

Halpern, D. F. (1997). Sex differences in intelligence. Implications for education. Am. Psychol. 52, 1091-1102.

Harrington, G. S., and Farias, S. T. (2008). Sex differences in language processing: functional MRI methodological considerations. J. Magn. Reson. Imaging 27, 1221-1228.

Haut, K. M., and Barch, D. M. (2006). Sex influences on material-sensitive functional lateralization in working and episodic memory: men and women are not all that different. Neuroimage 32, 411-422.

Hines, M. (2004). Brain Gender. Oxford: Oxford University Press.

Hyde, J. S. (2005). The gender similarities hypothesis. Am. Psychol. 60, 581-592.

Ihnen, S. K., Church, J. A., Petersen, S. E., and Schlaggar, B. L. (2009). Lack of generalizability of sex differences in the fMRI BOLD activity associated with language processing in adults. Neuroimage 45, 1020-1032.

Jordan-Young, R. M. (2010). Brain Storm: the Flaws in the Science of Sex Differences. Cambridge, MA: Harvard University Press.

Juraska, J. M. (1991). Sex differences in "cognitive" regions of the rat brain. Psychoneuroendocrinology 16, 105-109. 
Kaiser, A., Haller, S., Schmitz, S., and Nitsch, C. (2009). On sex/gender related similarities and differences in fMRI language research. Brain Res. Rev. 61, 49-59.

Koestner, R., and Aube, J. (1995). A multifactorial approach to the study of gender characteristics. J. Pers. 63, 681-710.

Koscik, T., O'Leary, D., Moser, D. J., Andreasen, N. C., and Nopoulos, P. (2009). Sex differences in parietal lobe morphology: relationship to mental rotation performance. Brain Cogn. 69, 451-459.

Kruijver, F. P. M., Zhou, J., Pool, C. W., Hofman, M. A., Gooren, L. J. G., and Swaab, J. D. F. (2000). Male-to-female transsexuals have female neuron numbers in a limbic nucleus. Clin. Endocrinol. Metab. 85, 2034-2041.

Lenroot, R. K., and Giedd, J. N. (2010). Sex differences in the adolescent brain. Brain Cogn. 72, 46-55.

Lin, Y., Ter Horst, G. J., Wichmann, R., Bakker, P., Liu, A., Li, X., and Westenbroek, C. (2009). Sex differences in the effects of acute and chronic stress and recovery after long-term stress on stress-related brain regions of rats. Cereb. Cortex 19, 1978-1989.

McCarthy, M. M. (2009). The two faces of estradiol: effects on the developing brain. Neuroscientist 15, 599-610.

McCarthy, M. M., and Konkle, A. T. (2005). When is a sex difference not a sex difference? Front. Neuroendocrinol. 26, 85-102.

McCarthy, M. M., Wright, C. L., and Schwarz, J. M. (2009). New tricks by an old dogma: mechanisms of the organizational/activational hypothesis of steroid-mediated sexual differentiation of brain and behavior. Horm. Behav. 55, 655-665.

McCormick, C. M., Smythe, J. W., Sharma, S., and Meaney, M. J. (1995). Sex-specific effects of prenatal stress on hypothalamic-pituitaryadrenal responses to stress and brain glucocorticoid receptor density in adult rats. Brain Res. Dev. Brain Res. 84, 55-61.

McLaughlin, K. J., Baran, S. E., and Conrad, C. D. (2009). Chronic stressand sex-specific neuromorphological and functional changes in limbic structures. Mol. Neurobiol. 40, 166-182.
Mitsushima, D., Masuda, J., and Kimura, F. (2003). Sex differences in the stress-induced release of acetylcholine in the hippocampus and corticosterone from the adrenal cortex in rats. Neuroendocrinology 78, 234-240.

Oomen, C. A., Girardi, C. E., Cahyadi, R., Verbeek, E. C., Krugers, H., Joels, M., and Lucassen, P. J. (2009). Opposite effects of early maternal deprivation on neurogenesis in male versus female rats. PLoS ONE 4, e3675. doi: 10.1371/journal.pone.0003675

Phoenix, C. H., Goy, R. W., Gerall, A. A., and Young, W. C. (1959). Organizing action of prenatally administered testosterone propionate on the tissues mediating mating behavior in the female guinea pig. Endocrinology 65, 369-382.

Plante, E., Schmithorst, V. J., Holland, S. K., and Byars, A. W. (2006). Sex differences in the activation of language cortex during childhood. Neuropsychologia 44, 1210-1221.

Reich, C. G., Taylor, M. E., and McCarthy, M. M. (2009). Differential effects of chronic unpredictable stress on hippocampal CB1 receptors in male and female rats. Behav. Brain Res. 203, 264-269.

Reiss, D. (2000). The interplay of genetic influences and social processes in developmental theory: specific mechanisms are coming into view. Dev. Psychopathol. 12, 357-374.

Rhodes, M. E., Creel, T. J., and Nord, A. N. (2009). Sex differences in CNS neurotransmitter influences on behavior. Horm. Brain Behav. 5, 2747-2785

Richardson, H. N., Zorrilla, E. P., Mandyam, C. D., and Rivier, C. L. (2006). Exposure to repetitive versus varied stress during prenatal development generates two distinct anxiogenic and neuroendocrine profiles in adulthood. Endocrinology 147, 2506-2517.

Rogers, L. (2001). Sexing the Brain. New York: Columbia University Press.

Rothstein, S., Simkins, T., and Nunez, J. L. (2008). Response to neonatal anesthesia: effect of sex on anatomical and behavioral outcome. Neuroscience 152, 959-969.

Rutter, M. (2010). Gene-environment interplay. Depress. Anxiety 27, 1-4.

Sakuma, Y. (2009). Gonadal steroid action and brain sex differentiation in the rat. J. Neuroendocrinol. 21, 410-414.

Sax, L. (2005). Why Gender Matters: What Parents and Teachers Need to Know about the Emerging Science of Sex Differences. New York: Boradway Books.

Shepard, K. N., Michopoulos, V. Toufexis, D. J., and Wilson, M. E. (2009). Genetic, epigenetic and environmental impact on sex differences in social behavior. Physiol. Behav. 97, 157-170.

Shors, T. J., Chua, C., and Falduto, J. (2001). Sex differences and opposite effects of stress on dendritic spine density in the male versus female hippocampus. J. Neurosci. 21, 6292-6297.

Simerly, R. B. (2002). Wired for reproduction: organization and development of sexually dimorphic circuits in the mammalian forebrain. Annu. Rev. Neurosci. 25 507-536.

Spence, J. T. (1993). Gender-related traits and gender ideology: evidence for a multifactorial theory. J. Pers. Soc. Psychol. 64, 624-635.

Suarez, J., Llorente, R., Romero-Zerbo S. Y., Mateos, B., Bermudez-Silva, F. J., de Fonseca, F. R., and Viveros, M. P. (2009). Early maternal deprivation induces genderdependent changes on the expression of hippocampal $\mathrm{CB}(1)$ and $\mathrm{CB}(2)$ cannabinoid receptors of neonatal rats. Hippocampus 19 , 623-632.

Swaab, D. F. (1995). Development of the human hypothalamus. Neurochem. Res. 20, 509-519.

Tannen, D. (1990). You Just Don't Understand: Women and Men in Conversation. New York: Ballantine Books.

Vathy, I. (2001). Prenatal morphine exposure induces age- and sexdependent changes in seizure susceptibility. Prog. Neuropsychopharmacol. Biol. Psychiatry 25, 1203-1226.

Vathy, I. (2002). Prenatal opiate exposure: long-term CNS consequences in the stress system of the offspring. Psychoneuroendocrinology 27, 273-283.

Vathy, I., and Katay, L. (1992). Effects of prenatal morphine on adult sexual behavior and brain catecholamines in rats. Brain Res. Dev. Brain Res. 68 , 125-131.
Vidal, C. (2005). Brain, sex and ideology. Diogenes 208, 127-133.

Viveros, M. P., Llorente, R., LopezGallardo, M., Suarez, J., BermudezSilva, F., De la Fuente, M., Rodriguez de Fonseca, F., and Garcia-Segura, L. M. (2009). Sex-dependent alterations in response to maternal deprivation in rats. Psychoneuroendocrinology 34(Suppl. 1), S217S226.

Whalen, R. E. (1974). "Sexual differentiation: models, methods and mechanisms," in Sex Differences in Behavior, eds R. C. Friedman, R. M. Riehart, and R. L. Van de Wiele (New York, NY: John Wiley \& Son), 467-481.

Wilber, A. A., Southwood, C. J., Sokoloff, G., Steinmetz, J. E., and Wellman, C. L. (2007). Neonatal maternal separation alters adult eyeblink conditioning and glucocorticoid receptor expression in the interpositus nucleus of the cerebellum. Dev. Neurobiol. 67 1751-1764.

Zuena, A. R., Mairesse, J., Casolini, P., Cinque, C., Alema, G. S., MorleyFletcher, S., Chiodi, V., Spagnoli, L. G., Gradini, R., Catalani, A., Nicoletti, F., and Maccari, S. (2008) Prenatal restraint stress generates two distinct behavioral and neurochemical profiles in male and female rats. PLoS ONE 3, e2170. doi: 10.1371/journal.pone.0002170

Conflict of Interest Statement: The author declares that the research was conducted in the absence of any commercial or financial relationships that could be construed as a potential conflict of interest.

Received: 14 July 2011; paper pending published: 12 August 2011; accepted: 30 August 2011; published online: 20 September 2011.

Citation: Joel D (2011) Male or female? Brains are intersex. Front. Integr. Neurosci. 5:57. doi: 10.3389/fnint.2011.00057

Copyright () 2011 Joel. This is an openaccess article subject to a non-exclusive license between the authors and Frontier Media SA, which permits use, distribution and reproduction in other forums, provided the original authors and source are credited and other Frontiers conditions are complied with. 